\title{
Sorption of Barium on Unconsolidated Glaciofluvial Deposits and Clay Minerals
}

\author{
By A. Grütter, H. R. von Gunten' ${ }^{1}$ and E. Rössler \\ Paul Scherrer Institut, CH-5232 Villigen PSI, Switzerland \\ 1 also at Laboratorium für Radiochemie, Universität Bern, Bern, Switzerland
}

(Received October 25, 1991; revised March 16, 1992)

Sorption / Barium / Glaciofluvial deposits /

Clay minerals / Synthetic groundwater /

Distribution ratios

\begin{abstract}
Drinking water is recovered in the alpine and peri-alpine regions to a large extent from shallow aquifers in unconsolidated deposits of quaternary glaciofluvial origin. Due to the importance of drinking water in the exposure pathway for many radionuclides we are studying sorption processes on samples from this aquifer and, in addition, on clay minerals.

Here, we report on batch measurements of sorption, desorption and exchange with barium in the concentration range of $1.0 \mathrm{E}-08$ to $1.0 \mathrm{E}-04 \mathrm{M}$ on glaciofluvial materials from Glattfelden, Switzerland, and on the clay minerals montmorillonite, illite and chlorite. For the aquifer material, the influence of grain size, mineralogy of the $<32-\mu \mathrm{m}$ size fraction and composition of the synthetic groundwater was investigated.

The results suggest that reversible cation-exchange mechanisms on clay minerals are responsible for the sorption behaviour of barium on the glaciofluvial aquifer material. Its dependence on the composition of the groundwater was reproduced with a 3-site model based on ion-exchange. The sorption isotherm for the aquifer material resembles that of the clay minerals illite and chlorite, but deviates considerably from that of montmorillonite.
\end{abstract}

\section{Introduction}

The radioactive isotopes of the alkaline earth elements strontium, barium and radium arise from the nuclear fuel cycle and may enter the environment. The fission product ${ }^{90} \mathrm{Sr}$ contributes significantly to the radiation hazard of irradiated fuel elements and reprocessing wastes during several hundred years of storage. Fission-produced $\mathrm{Ba}$-isotopes represent a minor health problem due to short half-lives $(<13 \mathrm{~d})$. Radium-226 results from uranium mining, the fabrication of nuclear fuel elements and ingrowth to stored nuclear fuel elements and wastes. It creates a long term radiation exposure problem and its behaviour in the geo- and biosphere should be known.

For sorption experiments suitable isotopes exist for strontium and barium, only. The literature about the sorption of strontium is plentiful, that about barium is very limited (Ref. [1 -3]). Isotherm measurements with radium are difficult to perform due to activity restrictions and measurement problems. This is reflected by the fact that, to our knowledge, only
Gillham et al. [1] have measured sorption isotherms for radium.

In the hope of enabling predictions on the migration behaviour of radium in the environment we investigate the sorption behaviour of its homologues barium and strontium. Here, we report on the sorption of barium on glaciofluvial deposits and on clay minerals. Quaternary glaciofluvial deposits abound in the peri-alpine countries and act as the final barrier before radionuclides may enter the biosphere. The glaciofluvial deposits consist of gravel, sand, silt and clay. Clay minerals are known to be very powerful sorbents. They are ubiquitous and will be used as back-fill materials in nuclear waste repositories.

\section{Experimental}

Materials

The glaciofluvial materials investigated were obtained from the water-saturated part of a percussion drilled core at Glattfelden ( $20 \mathrm{~km}$ north of Zürich). This material had been deposited by the Rhine glacier during the ice ages and was subsequently rearranged by rivers. The material from 22 to $24 \mathrm{~m}$ below the surface was subdivided into size fractions by wet sieving and sedimentation. Two size fractions, $<32 \mu \mathrm{m}$ and $250-$ $500 \mu \mathrm{m}$, were investigated. The $250-500-\mu \mathrm{m}$ material was cleaned of finer material by ultrasonic treatments. The $<32-\mu \mathrm{m}$ size fraction had the following mineralogical composition: $31 \%$ of quartz, $36 \%$ of calcite, $7 \%$ of dolomite, $11 \%$ of albite, $9 \%$ of illite, $5 \%$ of chlorite and $1 \%$ of montmorillonite (Tj. Peters, private communication). Due to difficulties in grinding the $250-500-\mu \mathrm{m}$ size fraction the mineralogical composition of this glaciofluvial material has not been determined. The study includes also experiments with $<32-$ $\mu \mathrm{m}$ glaciofluvial material which had been chemically treated in the following way:

- In order to reduce the amounts of exchangeable barium, strontium and possibly other interfering cations a portion of the $<32-\mu \mathrm{m}$ glaciofluvial material was subjected to five exchanges with $2 \mathrm{M}$ sodium chloride solutions containing $0.002 \mathrm{M}$ of potassium chloride and subsequently equilibrated with synthetic groundwater. Potassium chloride was added to prevent changes in the sorption 
Table 1. Cation-exchange capacities $C$ determined by sodium saturation and concentrations of exchangeable barium in the solid at the beginning of the sorption step with synthetic groundwater SGW

\begin{tabular}{|c|c|c|}
\hline Material & $\begin{array}{c}C \\
\mathrm{meq} / \mathrm{g}\end{array}$ & $\begin{array}{c}{[\mathrm{Ba}]} \\
\mu \mathrm{mole} / \mathrm{g}\end{array}$ \\
\hline \multicolumn{3}{|l|}{ Glaciofluvial materials: } \\
\hline $\begin{array}{l}250-500 \mu \mathrm{m} \\
<32 \mu \mathrm{m} \\
\mathrm{NaCl}-\mathrm{treated} \\
\text { free of carbonates } \\
\text { free if carbonates and } \\
\text { oxides } \\
\text { free of carbonates, oxides } \\
\text { and organic materials }\end{array}$ & $\begin{array}{l}0.0104 \\
0.049 \\
0.051 \\
0.085 \\
\\
0.066\end{array}$ & $\begin{array}{l}0.0200 \\
0.195 \\
0.039 \\
0.046 \\
0.0165\end{array}$ \\
\hline \multicolumn{3}{|l|}{ Clay minerals: } \\
\hline $\begin{array}{l}\text { montmorillonite } \\
\text { illite } \\
\text { chlorite, }<40 \mu \mathrm{m} \\
\text { chlorite, ground to }<2 \mu \mathrm{m}\end{array}$ & $\begin{array}{l}0.89 \\
0.36 \\
0.0145 \\
0.38\end{array}$ & $\begin{array}{l}0.0123 \\
0.204 \\
0.0125 \\
0.073\end{array}$ \\
\hline
\end{tabular}

properties of the clay minerals, especially of illite, due to desorption of potassium. After each treatment, the phases were separated by centrifuging at an acceleration of $11^{\prime} 500 \mathrm{~g}$ for 40 minutes and decanting the solution. This $\mathrm{NaCl}$-treated material has the same mineralogical composition as the untreated $<32-\mu \mathrm{m}$ glaciofluvial material.

- The carbonates were removed from an other portion of the untreated $<32-\mu \mathrm{m}$ glaciofluvial material by bubbling carbon dioxide gas through a solution containing small amounts of calcium, magnesium and potassium chloride and $1.6 \mathrm{mmol} / \mathrm{l}$ of sodium hydrogen carbonate to avoid $\mathrm{pH}$ values below 5.0. The solution was renewed until its calcium content no longer increased.

- Iron and manganese oxides were removed from a portion of the carbonate free glaciofluvial material according to the procedure of Anderson and Jenne [4].

- Finally, organic substances were destroyed with hydrogen peroxide (procedure of Kunze and Dixon [5]) in half of the glaciofluvial material free of carbonates and oxides.

For comparison, experiments were also conducted with a few clay minerals: a montmorillonite from Crook County, Wyoming, USA, an illite from Puyen-Velay, France, and a chlorite [6] from Grimsel, Switzerland.

The cation-exchange capacities $C$ were determined by sodium saturation in $1 \mathrm{M}$ sodium acetate (procedure of Chapman [7], adapted for small samples using ${ }^{22} \mathrm{Na}$ ) and are shown in Table 1.

\section{Synthetic groundwater}

Synthetic groundwater (SGW) with the following composition (in meq/l) was used for the majority of the experiments: $\mathrm{Ca}^{2+}, 4.50 ; \mathrm{Mg}^{2+}, 1.69 ; \mathrm{Na}^{+}, 0.67$; $\mathrm{K}^{+}, 0.084 ; \mathrm{Cl}^{-}, 6.52$; alkalinity, $0.42 ; \mathrm{pH} 7.9$. This is typical of the composition of groundwaters of calciterich aquifers with the exception that the bicarbonate ion was largely replaced by the chloride ion. This

Table 2. Parameters of a 2 nd order fit to the experimental sorption data, range of barium concentrations in solution (M) at equilibrium and mean values for the exponent $n$ in the isotherm equation of Freundlich

\begin{tabular}{|c|c|c|c|c|c|c|}
\hline \multirow[t]{2}{*}{ Material } & \multirow{2}{*}{$\begin{array}{l}\text { Synthetic } \\
\text { groundwater } \\
\text { (see text) }\end{array}$} & \multicolumn{3}{|c|}{ 2nd order fit** } & \multirow{2}{*}{$\begin{array}{l}\text { Range of } \\
\log ([\mathrm{Ba}])\end{array}$} & \multirow[t]{2}{*}{$n$} \\
\hline & & $\mathbf{a}$ & b & c & & \\
\hline
\end{tabular}

\section{Glaciofluvial materials:}

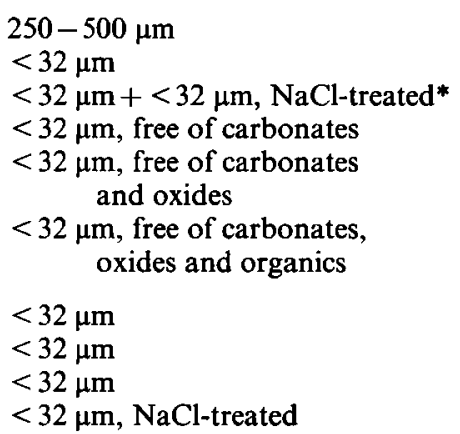

\section{Clay minerals:}

montmorillonite

illite

$<40$ - $\mu$ m chorite

$<2-\mu$ m chlorite

$\begin{array}{crrrrr}\text { SGW } & -1.870 & 0.2720 & -0.02197 & -7.05 /-4.02 & 0.52 \\ \text { SGW } & -1.126 & 0.2863 & -0.01868 & -6.53 /-4.12 & 0.49 \\ \text { SGW } & -1.594 & 0.1009 & -0.03649 & -7.54 /-4.12 & 0.52 \\ \text { SGW } & -1.470 & 0.0726 & -0.04031 & -7.60 /-4.10 & 0.55 \\ \text { SGW } & -1.849 & -0.0666 & -0.05277 & -8.02 /-4.09 & 0.58 \\ \text { SGW } & -1.815 & -0.0410 & -0.05138 & -8.11 /-4.09 & 0.59 \\ \text { SGW-1/3K } & -1.088 & 0.3067 & -0.01546 & -6.55 /-4.12 & 0.47 \\ \text { SGW-1/2Ca } & -0.881 & 0.3303 & -0.01454 & -6.63 /-4.16 & 0.49 \\ \text { SGW-2Ca } & -1.313 & 0.2601 & -0.02171 & -6.43 /-4.09 & 0.49 \\ \text { SGW-HCO3 } & -1.408 & 0.1618 & -0.03326 & -7.29 /-4.11 & 0.54\end{array}$

* Fit to the combined data for untreated and $\mathrm{NaCl}$-treated $<32-\mu \mathrm{m}$ material, whose isotherms agree within experimental errors.

** Fit to the experimental data using the equation $\log \left([\mathrm{Ba}]_{\mathrm{s}}\right)=\mathrm{a}+\mathrm{b} \cdot \log ([\mathrm{Ba}])+\mathrm{c} \cdot(\log ([\mathrm{Ba}]))^{2}$. 


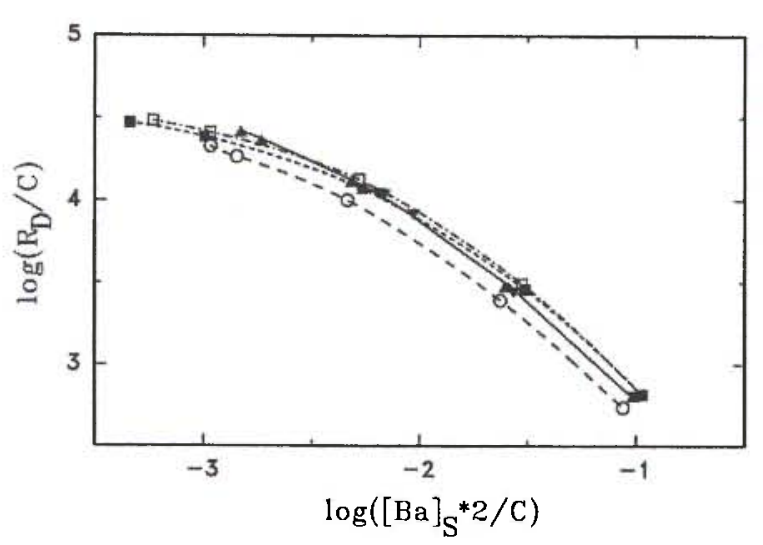

Fig. 1. Sorption data for barium in synthetic groundwater on $<32-\mu \mathrm{m}$ glaciofluvial material subjected to various chemical treatments; for clarity desorption data are omitted; distribution ratios normalized with the cation exchange capacity $C$.

-, $\boldsymbol{\Delta}$ u untreated and $\mathrm{NaCl}$-treated, respectively;

- - 0 free of carbonates;

- - $\square$ free of carbonates and oxides;

-

allowed experimenting at ambient carbon dioxide pressure. This synthetic groundwater is slightly undersaturated with respect to calcite. In the experiments dealing with the influence of solution chemistry the composition of the synthetic groundwater was changed. Details will be given later, together with the results of these experiments.

\section{Procedure and calculations}

The procedure used was very similar to that in Ref. [8]. In a batch method 100 to $200 \mathrm{mg}$ of solid material were contacted with $20 \mathrm{ml}$ of synthetic groundwater in a closed 40-ml FEP (tetrafluorethylene-hexafluorpropylene) centrifuge tube. The solid material remained within this tube throughout the sequence: (1) pretreatment, (2) sorption, (3) desorption and (4) $1-3$ exchanges. The tubes were rotated head-over-end at $1 \mathrm{rpm}$. After each step the phases were separated by centrifuging at approximately $20^{\prime} 000 \mathrm{~g}$ in a cooling centrifuge for 40 minutes and withdrawal of the liquid. $5 \mathrm{ml}$ of solution were used to measure the ${ }^{133} \mathrm{Ba}$ tracer on an intrinsic Ge-detector.

During the pretreatment (3 steps for the glaciofluvial materials and 10 steps for the clay minerals) the solid material was equilibrated with the synthetic groundwater with respect to the major cations. For the sorption step, synthetic ground water containing barium labelled with ${ }^{133} \mathrm{Ba}$ was added (concentration range: $2.5 \mathrm{E}-08-1.0 \mathrm{E}-04 \mathrm{M}$ ). The barium content in the synthetic groundwater for desorption amounted to about $2.5 \mathrm{E}-08 \mathrm{M}$ and was due to impurities in the chemicals. For the exchange experiments synthetic groundwater with a barium concentration of 1.0E-04 $\mathrm{M}$ was used. In most cases the sorption and desorption steps lasted 14 days and the exchange steps 21 days. Exceptions will be mentioned in the text.

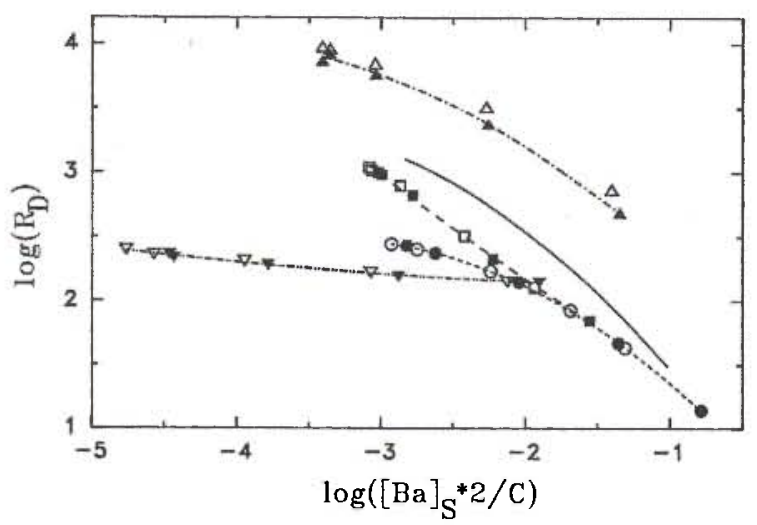

Fig. 2. Sorption $(\boldsymbol{\nabla}, \boldsymbol{\bullet}, \boldsymbol{\square}, \mathbf{\Delta})$ and desorption $(\nabla, O, \square, \Delta)$ data for barium on clay minerals and on $<32-\mu \mathrm{m}$ glaciofluvial material in synthetic groundwater.

$-\cdots-\nabla, \nabla$ montmorillonite;

$\begin{aligned} & -- \\ & -\end{aligned}, \mathrm{D}$ illite;

- $-\Delta, \Delta<2-\mu \mathrm{m}$ chlorite;

$<32-\mu \mathrm{m}$ material, untreated and $\mathrm{NaCl}$-treated.

Data treaţment was described in Ref. [8]. At low barium concentrations the amount of exchangeable barium introduced with the solid material is not negligeable compared to the amount of barium added with the synthetic groundwater. In fact, at barium concentrations of $2.5 \mathrm{E}-08 \mathrm{M}$, the barium concentration in the solution increased in nearly all cases during the sorption step while the concentration of the ${ }^{133} \mathrm{Ba}$ tracer decreased. Typical values for the concentration of exchangeable barium in the solid $\left([\mathrm{Ba}]_{3}^{0}\right)$ are included in Table 1.

\section{Results and discussion}

The concentration of barium in the solid (mmole/g) is denoted by $[\mathrm{Ba}]_{\mathrm{s}}$ and that in solution $(\mathrm{M})$ by $[\mathrm{Ba}]$. The distribution ratio $(\mathrm{ml} / \mathrm{g})$ is defined by $R_{D}=[\mathrm{Ba}]_{\mathrm{S}} /$ [Ba] and the loading of the solid with barium by $[\mathrm{Ba}]_{\mathrm{s}} * 2 / C . C$ is the cation-exchange capacity (meq/g). In the Figures we present the distribution ratios as a function of the loadings of the solid with barium in log$\log$ plots. Differences between data are emphasized in this representation. We call the resulting curves "sorption curves" to distinguish them from "isotherms" defined by $[\mathrm{Ba}]_{s}=f([\mathrm{Ba}])$. Similarity in shape of the sorption curves is equivalent to similarity in shape of the isotherms. A linear isotherm $[\mathrm{Ba}]_{\mathrm{s}}=$ $a *[\mathrm{Ba}]$ is characterized by a constant distribution ratio at all loadings, i.e. a horizontal line in the Figures, and is equivalent to a Freundlich isotherm with an exponent of 1.0 .

Table 2 summarizes some values characterizing the sorption of barium: Parameters obtained from a second order polynome fit to the experimental isotherm data are included in this Table. Values of $\log [\mathrm{Ba}]_{S}$ calculated with these parameters do not deviate by more than 0.02 from the experimentally determined values. Table 2 also gives the range of experimental 
Table 3. Distribution ratios for $<32-\mu \mathrm{m}$ glaciofluvial material and clay minerals calculated for two concentrations and two loadings of barium from least square fits to the experimental data (Table 2 and Figure 3); values in brackets are extrapolated

\begin{tabular}{|c|c|c|c|c|}
\hline \multirow[t]{2}{*}{ Material } & \multicolumn{2}{|c|}{$\log ([\mathrm{Ba}])$} & \multicolumn{2}{|c|}{$\log \left([\mathrm{Ba}]_{\mathrm{s}} * 2 / \mathrm{C}\right)$} \\
\hline & -7.0 & -4.5 & -3.0 & -1.5 \\
\hline & \multicolumn{4}{|c|}{$R(D)$-values } \\
\hline $\begin{array}{l}<32 \mu \mathrm{m}, \mathrm{NaCl} \text {-treated } \\
\text { montmorillonite } \\
\text { illite } \\
<40-\mu \mathrm{m} \text { chlorite } \\
<2-\mu \mathrm{m} \text { chlorite }\end{array}$ & $\begin{array}{r}800 \\
212 \\
\left(1^{\prime} 320\right) \\
218 \\
4^{\prime} 030\end{array}$ & $\begin{array}{r}51 \\
141 \\
99 \\
23 \\
(365)\end{array}$ & $\begin{array}{c}\left(1^{\prime} 520\right) \\
162 \\
950 \\
(284) \\
5^{\prime} 720\end{array}$ & $\begin{array}{c}116 \\
(133) \\
62 \\
62 \\
665\end{array}$ \\
\hline $\begin{array}{l}<40-\mu \text { m chlorite } \\
<2-\mu \text { m chlorite }\end{array}$ & \multicolumn{4}{|c|}{$R(D) / C$-values } \\
\hline $\begin{array}{l}<32 \mu \mathrm{m}, \mathrm{NaCl} \text {-treated } \\
\text { montmorillonite } \\
\text { illite } \\
<40-\mu \mathrm{m} \text { chlorite } \\
<2-\mu \mathrm{m} \text { chlorite }\end{array}$ & $\begin{array}{l}16^{\prime} 300 \\
239 \\
\left(3^{\prime} 650\right) \\
15^{\prime} 000 \\
10^{\prime} 600\end{array}$ & $\begin{array}{r}1^{\prime} 040 \\
159 \\
274 \\
1^{\prime} 610 \\
(960)\end{array}$ & $\begin{array}{c}\left(31^{\prime} 000\right) \\
182 \\
2^{\prime} 650 \\
\left(19^{\prime} 500\right) \\
15^{\prime} 100\end{array}$ & $\begin{array}{r}2^{\prime} 370 \\
(150) \\
172 \\
4^{\prime} 250 \\
1^{\prime} 750\end{array}$ \\
\hline
\end{tabular}

equilibrium concentrations of barium. The lower end of this range is largely determined by the amount of exchangeable barium introduced with the solid and the distribution ratio at this concentration. At the upper end the barium concentrations for montmorillonite and the $<2-\mu \mathrm{m}$ chlorite are clearly lower than for the other materials. This is due to a combination of high cation-exchange capacities combined with high distribution ratios. Mean values for the exponent in the isotherm equation of Freundlich are given in the last column of Table 2 .

The sorption of barium is almost completely reversible as was demonstrated by the exchange experiments. This is in sharp contrast to the behaviour of cesium [8]. This change in behaviour was not unexpected since the sorption of cesium and, as will be shown below, of barium is dominated by the clay minerals: the irreversible behaviour of cesium was explained [8] by trapping within the structure due to collapse of the layer spacing in regions with vermiculite-like character [9], whereas barium can be used at higher temperatures to replace potassium in muscovites thereby expanding the layer spacing (e.g. [10]). The amount of ${ }^{133} \mathrm{Ba}$ 'irreversibly' sorbed during the sorption step was estimated using the results of the exchange experiments. The results can be summarized as follows:

- The amount of 'irreversibly' sorbed ${ }^{133} \mathrm{Ba}$ did not exceed a few percent. It decreased in the sequence 1st, 2nd and 3rd exchange indicating that this small amount of ${ }^{133} \mathrm{Ba}$ is not truely irreversibly sorbed but exchanges very slowly.

- The sorption and desorption data remain nearly unaffected if corrections for the 'irreversibly' sorbed ${ }^{133} \mathrm{Ba}$ are applied. However, the effects of these corrections are noticeable for the exchange experiments.

\section{Influence of mineralogy}

The influence of changes in the mineralogy of the $<32-\mu \mathrm{m}$ glaciofluvial material on the sorption of barium will be considered first. These changes were achieved by chemical treatments. The concentration of sorption sites varies with the progression through chemical treatments. The cation-exchange capacity is used as a measure of the concentration of sorption sites. Normalizing the distribution ratios with the cation-exchange capacities moves the curves close together as shown in Figure 1. The sorption curves of the untreated and the $\mathrm{NaCl}$-treated glaciofluvial materials agree within experimental errors, as expected. Since the sorption curves for all chemically treated glaciofluvial materials are very similar, neither the carbonates, nor the iron and manganese oxides, nor the organic substances contribute significantly to the sorption of barium. Therefore, clay minerals must be the main sorbing component. Close inspection of Figure 1 reveals that the curve for the untreated and $\mathrm{NaCl}$ treated glaciofluvial materials (solid line) is steeper than that for the glaciofluvial material free of carbonates, oxides and organic substances. This effect is more clearly seen if the sorption curves are made to coincide at high barium concentrations. Then small differences appear: the curves become flatter at low loadings with progression through the chemical treatments. This means that either the number of high energy sorption sites decreased during the chemical treatments and/or their sorption energy was lowered. The latter statement only makes sense if the sorbents exhibit a restricted number of sorption sites with definite sorption energies instead of a continuous spectrum. Models with 3 types of sorption sites are quite often used, e.g. in Ref. [3, 11, 12], and in this work for modelling the influence of solution chemistry. The mean values for 


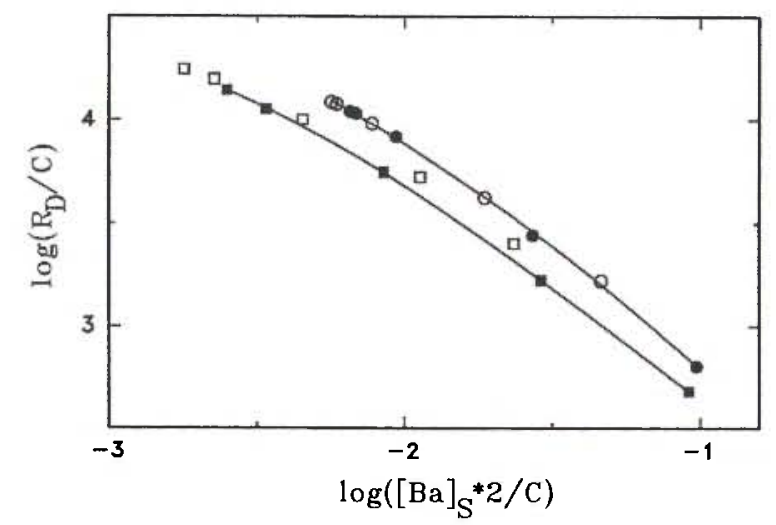

Fig. 3. Sorption $(\boldsymbol{O}, \mathbf{\square})$ and desorption $(O, \square)$ data for barium on 2 grain size fractions of glaciofluvial deposits in synthetic groundwater; distribution ratios normalized with the cation ex-

- $\bigcirc \quad<32-\mu \mathrm{m}$ material; change capacity $C$.

घ, $\quad 250-500-\mu \mathrm{m}$ material.

the exponent $n$ in the Freundlich equation amount to 0.5 to 0.6 (Table 2). Therefore, the isotherms of the $<32-\mu \mathrm{m}$ glaciofluvial materials are strongly nonlinear. The value of $n$ and the parameter $c$ in the 2nd order fit increase with succeeding steps of chemical treatments.

In Figure 2 the sorption and desorption curves for barium in synthetic groundwater obtained with clay minerals are presented and compared to that of the $\mathrm{NaCl}-$ treated $<32-\mu \mathrm{m}$ glaciofluvial material (solid line). While the isotherm of montmorillonite is nearly linear (mean value for the exponent of the Freundlich isotherm $n=0.93$ ) those of the other clay minerals are non-linear ( $n$ about 0.6 ). Grinding of the $<40-\mu \mathrm{m}$ chlorite to $<2 \mu \mathrm{m}$ changes the shape of the sorption curve to a much smaller degree than we observed for the sorption of cesium [8]. The sorption curve of the $<32-\mu \mathrm{m}$ glaciofluvial material has a shape intermediate between those for illite and the chlorites.

For montmorillonite, illite and the $<40-\mu \mathrm{m}$ chlorite the distribution ratio remained unchanged from 2 to 14 days during sorption and desorption. In case of the $<2-\mu \mathrm{m}$ chlorite, constant values were not reached within 14 days for sorption and 28 days for desorption. It is therefore not surprising that the sorption and desorption data differ for the $<2-\mu \mathrm{m}$ chlorite, whereas they are indistinguishable for the other clay minerals.

It is more difficult to compare values instead of shapes: The result of such a comparison depends on the choice among the 4 combinations shown in Table 3 $\left(R_{D}, R_{D} / C,[\mathrm{Ba}],[\mathrm{Ba}]_{S} * 2 / C\right)$. For practical purposes the distribution ratio $\left(R_{D}\right)$ as a function of the concentration of barium in the groundwater [Ba] is the appropriate choice. Although this relationship is not shown in the figures, it can easily be obtained using the parameters of the 2nd order fit (Table 2) to calculate $\log [\mathrm{Ba}]_{\mathbf{S}}$ since $\log \bar{\kappa}_{D}=\log [\mathrm{Ba}]_{\mathbf{S}}-\log ([\mathrm{Ba}])$.

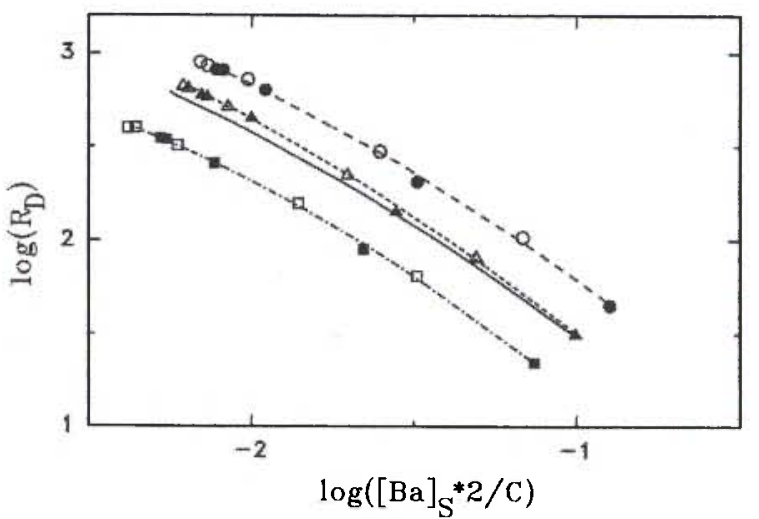

Fig. 4. Sorption $(\boldsymbol{\theta}, \mathbf{n}, \Delta)$ and desorption $(O, \square, \triangle)$ data for barium on $<32-\mu \mathrm{m}$ glaciofluvial material in synthetic groundwater of varying composition.

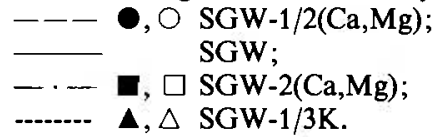

\section{Influence of grain size}

The glaciofluvial deposits are very heterogeneous with respect to grain size and mineralogy. In the study of the sorption of cesium [8] we have shown that a single isotherm was obtained for all size fractions from $<32 \mu \mathrm{m}$ up to $1000-2000 \mu \mathrm{m}$, if the distribution ratios are normalized with the cation-exchange capacity. In order to verify this result for the sorption of barium, sorption curves were measured for two size fractions: $<32 \mu \mathrm{m}$ and $250-500 \mu \mathrm{m}$. Normalization with the cation-exchange capacity reduces largely, though not completely, the differences observed (Figure 3). The shapes of the sorption curves for the two glaciofluvial materials are very similar. This is an indication that the clay minerals in both size fractions are similar. We suspect that the sorptive capacity of the $250-500-\mu \mathrm{m}$ glaciofluvial material is mainly due to clays retained in pores and cavities. This hypothesis is in agreement with the slow kinetics of the 250$500 \mu \mathrm{m}$ glaciofluvial material for which a duration of 112 days was chosen for each step. However equilibrium was probably not reached, since the desorption values are shifted towards higher values. The kinetics for the $<32-\mu \mathrm{m}$ glaciofluvial material are much faster: the results obtained after 14 days are indistinguishable from those after 56 days.

\section{Influence of solution chemistry}

Groundwaters of the Swiss peri-alpine plains vary in composition with respect to cations. Moreover they contain much higher concentrations of bicarbonate ions and therefore have a lower $\mathrm{pH}$ than the synthetic groundwater (SGW) of this study. In order to investigate the effects of variations in solution chemistry we measured sorption curves for the $<32-\mu \mathrm{m}$ glaciofluvial material also in synthetic groundwater with halfed and doubled calcium and magnesium ion contents, 


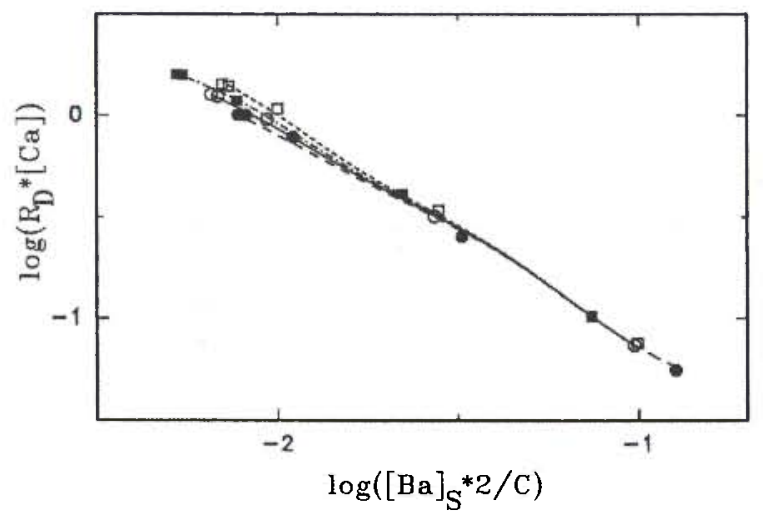

Fig. 5. Sorption data for barium on $<32-\mu \mathrm{m}$ glaciofluvial material in synthetic groundwater of varying composition; distribution ratios multiplied with the concentration of calcium in solution; the curves are calculated with the 3-site model.

$\begin{array}{ll}--1 & \text { SGW-1/2(Ca,Mg) } \\ -\cdots & \text { SGW; } \\ -\cdots & \text { SGW-2(Ca,Mg); } \\ \cdots & \text { SGW-1/3K. }\end{array}$

denoted by SGW-1/2(Ca,Mg) and SGW-2(Ca,Mg) respectively, and with a potassium ion content of one third (SGW-1/3K). In an experiment in a glove box the carbon dioxide pressure was increased to 0.02 bar. In this synthetic groundwater (SGW-HCO3) the contents of the major cations were identical to those in SGW. However, the alkalinity increased to $4.23 \mathrm{meq} / 1$ and the $\mathrm{pH}$ decreased to 7.1.

Figure 4 presents the results of the experiments with varying contents of the major cations. Variations of calcium and magnesium influence the sorption curves strongly, whereas changes in potassium cause much smaller effects. This is the reverse of the behaviour observed for cesium [8]. Figure 4 shows that the distribution ratios in solutions with halfed or doubled calcium and magnesium contents deviate from those in SGW by roughly a factor of 2 . This suggests that the sorption of barium is mainly governed by the cation-exchange reaction

$$
\mathrm{Ba}^{2+}+\mathrm{Ca}-\mathrm{S} \leftrightarrow \mathrm{Ba}-\mathrm{S}+\mathrm{Ca}^{2+}
$$

$\mathrm{Ca}-\mathrm{S}$ and $\mathrm{Ba}-\mathrm{S}$ denote sorbed species. The symbol $\mathrm{Ca}$ stands for calcium and possibly magnesium. On the basis of our experiments, it is not possible to distinguish between these two ions. However, due to its much higher concentration, calcium is expected to be the dominant interfering cation. The equilibrium constant for the above reaction, ignoring activity coefficients, is given by

$$
K_{\mathrm{Ba}, \mathrm{Ca}}=\left([\mathrm{Ba}]_{\mathrm{s}} /[\mathrm{Ba}]\right) *\left([\mathrm{Ca}] /[\mathrm{Ca}]_{\mathrm{s}}\right) .
$$

The first term on the right hand side is equal to the distribution ratio $R_{D}$. If the above reaction were the only one to consider, then the distribution ratio multiplied with the calcium concentration in the solution should be independant of the content of calcium and magnesium for a given loading with barium, since $[\mathrm{Ca}]_{\mathrm{s}}=C / 2-[\mathrm{Ba}]_{\mathrm{s}}$. In Figure 5 the experimental data

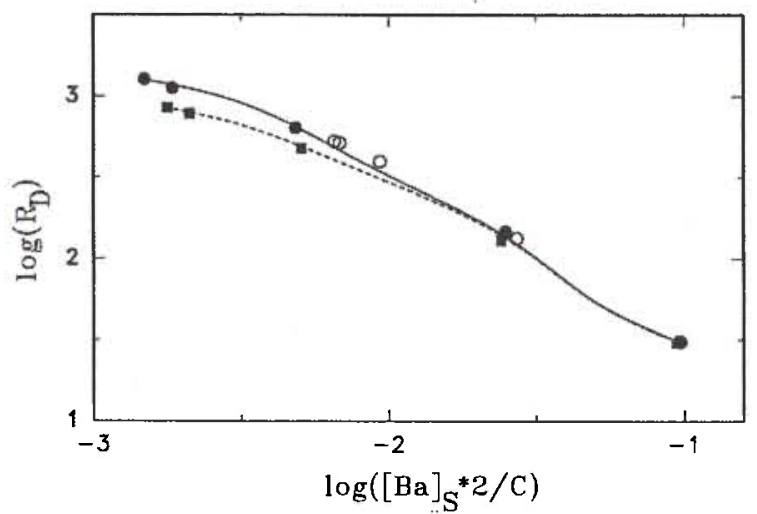

Fig. 6. Sorption data for barium on $<32-\mu \mathrm{m}$ glaciofluvial material in synthetic groundwater with carbon dioxide at atmospheric (SGW) and at an elevated (0.02 bar, SGW-HCO3) partial pressure; the curves are calculated with the 3-site model. O $\quad<32-\mu \mathrm{m}$ material in SGW;

$\mathrm{NaCl}$-treated $<32-\mu \mathrm{m}$ material in SGW;

$\mathrm{NaCl}$-treated $<32-\mu \mathrm{m}$ material in SGW-HCO3.

are plotted accordingly and, indeed, only at low loadings small deviations from a single sorption curve are observed. In order to take into account an interference of potassium ions the following reaction was also considered:

$$
2 \mathrm{~K}^{+}+\mathrm{Ca}-\mathrm{S} \leftrightarrow 2 \mathrm{~K}-\mathrm{S}+\mathrm{Ca}^{2+} .
$$

The equilibrium constant is given by

$$
K_{\mathrm{K}, \mathrm{Ca}}=\left([\mathrm{K}]_{\mathrm{s}} /[\mathrm{K}]\right)^{2} *\left([\mathrm{Ca}] /[\mathrm{Ca}]_{\mathrm{s}}\right) \text {. }
$$

We have applied this scheme to a model with 3 types of sorption sites. The influence of potassium ions was limited to the first type of sites having the highest equilibrium constant for barium $K_{\mathrm{Ba} . \mathrm{Ca}}$. $[\mathrm{Ca}]_{\mathrm{S}}$ in equation (2) and (4) is defined in the following way: 1st type of sites:

$$
[\mathrm{Ca}]_{\mathrm{S}, 1}=\left(\mathrm{C}_{1}-[\mathrm{K}]_{\mathrm{s}, 1}\right) / 2-[\mathrm{Ba}]_{\mathrm{S}, 1}
$$

2nd or 3rd type of sites:

$$
[\mathrm{Ca}]_{\mathrm{S}, \mathrm{i}}=\mathrm{C}_{\mathrm{i}} / 2-[\mathrm{Ba}]_{\mathrm{S}, \mathrm{i}} \text {. }
$$

The experimentally determined cation-exchange capacity $C$ and the overall distribution ratio for barium $R_{D}$ are equal to the sum of the individual entities for the 3 types of sorption sites:

$$
\begin{aligned}
& C=C_{1}+C_{2}+C_{3} \\
& R_{D}=R_{D, 1}+R_{D, 2}+R_{D, 3} .
\end{aligned}
$$

For the calculations the activity coefficients of the cations in solution were taken into account using the approximation of Davies as given in Ref. [13]. The equilibrium constants for the sorption of barium and of potassium were determined applying equations (2) and (4) to the sorption curves obtained in SGW-1/2Ca and SGW-1/3K. The cation-exchange capacities for the 3 types of sites were chosen so that the fit to the experimental data in SGW-1/2Ca was as good as possible. In Figure 5 the experimental data are compared with the results of these calculations. The model 
based on the two exchange reactions given above reproduces the variations in the experimental values very well. The observed differences are caused by the different $[\mathrm{K}] /[\mathrm{Ca}]$-ratios of the synthetic groundwaters: Without the interference of potassium a single curve in Figure 5 would have been the result of the calculations.

If the partial pressure of carbon dioxide is increased from atmospheric to 0.02 bar (SGW-HCO3), the sorption of barium is reduced at low loadings, but remains unchanged at high loadings as shown in Figure 6. We have again applied the 3-site model with two ion-exchange reactions. For the second exchangereaction (Eqs. (3) to (5)) potassium is replaced by hydrogen. The observed effects are again well reproduced by the model. This is a strong indication that the decreased sorption of barium in SGW-HCO3 compared to that in SGW is caused by an increased interference of the hydrogen ions. Speciation calculations show that the percentages of uncomplexed ions are very high and nearly identical for barium and the major cations in SGW and SGW-HCO3.

The calculated sorption curve for the $\mathrm{NaCl}$-treated $<32-\mu \mathrm{m}$ glaciofluvial material in SGW is wavy contrary to the curve suggested by the experimental data. It was not possible to find a set of cation-exchange capacities, for which this effect disappeared. A similar though less pronounced effect is observed for the untreated $<32-\mu \mathrm{m}$ glaciofluvial material at high loadings, as shown in Figure 5. More than 3 types of sorption sites are needed to avoid the wavy shape of the calculated sorption curves. Probably, the $<32-\mu \mathrm{m}$ glaciofluvial material has sorption sites with a broad spectrum of sorption energies for barium. The 3-site model used here is merely an approximation to reality.

\section{Conclusions}

- The isotherms for the sorption of barium in synthetic groundwater on size fractions of $<32 \mu \mathrm{m}$ and $250-500 \mu \mathrm{m}$ of quaternary glaciofluvial materials are non-linear.

- Normalization with the cation-exchange capacity reduces the differences between the isotherms of these two size fractions considerably.

- The isotherms of the chemically treated $<32-\mu \mathrm{m}$ glaciofluvial material differ only very slightly, if the differences in cation exchange capacity are taken into account. This demonstrates that neither the carbonates, nor the iron and manganese oxides, nor organic substances contribute substantially to the sorption of barium. Exchange reactions on the clay minerals are therefore the main process.

- The sorption of barium on the clay mineral montmorillonite is characterized by a nearly linear iso- therm, whereas those for illite and chlorite are strongly non-linear. This fact, together with the low abundance of montmorillonite, suggests that illite and chlorite dominate the sorption of barium on the glaciofluvial materials investigated.

- Desorption and exchange experiments demonstrated, that the sorption of barium is practically reversible at all concentrations investigated.

- Realistic variations in the composition of the synthetic groundwater show that the sorption of barium on the $<32-\mu \mathrm{m}$ glaciofluvial material depends strongly on the calcium and possibly magnesium content of the synthetic groundwater, whereas the concentration of potassium ions and the $\mathrm{pH}$ cause minor changes. The effects can be reproduced with a model based on ion exchange reactions.

\section{Acknowledgements}

The authors acknowledge the Institute for Aquatic Sciences (EAWAG) for supplying samples and the Swiss National Science Foundation for partial support.

\section{Literature}

1. Gillham, R. W., Sharma, H. D., Reddy, M. R., Cooper, E. L., Cherry, J. A.: Barium and Radium Migration in Unconsolidated Canadian Geological Materials, Atomic Energy Control Board, Ottawa, Ontario (Canada), INFO0048, 1981.

2. Eylem, C., Erten, H. N., Göktürk, H.: Analyst 114, 351 (1989).

3. Eylem, C., Erten, H. N., Göktürk, H.: J. Environ. Radioactivity 11, 183 (1990).

4. Anderson, B. J., Jenne, E. A.: Soil Sci. 109, 163 (1970)

5. Kunze, G. W., Dixon, J. B.: Pretreatment for Mineralogical Analysis in: Methods of Soil Analysis, Part 1, 2nd ed., (Klute, A., ed.), Amer. Soc. Agron., Soil Sci. Soc. America Publ., Madison 1986.

6. Grütter, A., von Gunten, H. R., Rössler, E.: Clays Clay Miner. 34, 677 (1986).

7. Chapman, H. D.: Cation-Exchange Capacity by Sodium Saturation, in: Methods of Soil Analysis, Part 2 (Black, C. A., ed.), Amer. Soc. Agron. Publ., Madison 1965.

8. Grütter, A., von Gunten, H. R., Kohler, M., Rössler, E.: Radiochim. Acta 50, 177 (1990).

9. Jacobs, D. G., Tamura, T.: Trans. 7th Int. Congr. Soil Sci., Madison 1960, Vol. 2, p. 206-214, Internat. Soc. Soil Sci., Elsevier, Amsterdam.

10. Graf von Reichenbach, H., Rich, C. I.: Clays Clay Miner. 17, 23 (1969)

11. Bolt, G. H., Sumner, M. E., Kamphorst, A.: Soil Sci. Soc. Am. Proc. 27, 294 (1963).

12. Brouwer, E., Baeyens, B., Maes, A., Cremers, A.: J. Phys. Chem. 87, 1213 (1983).

13. Stumm, W., Morgan, J. J.: Aquatic Chemistry, p. 135, John Wiley and Sons, New York 1981. 
